\title{
From Sunrise to Sunset in the California Drift Gillnet Fishery: An Examination of the Effects of Time and Area Closures on the Catch and Catch Rates of Pelagic Species
}

\author{
LAURA C. URBISCI, STEPHEN M. STOHS, and KEVIN R. PINER
}

\section{Introduction}

The Pacific Fishery Management Council's Fishery Management Plan for U.S. West Coast Highly Migratory Species (NMFS, 2007) describes five fisheries for highly migratory species (HMS), defined by the combination of target species and gear type. The largemesh California drift gillnet (DGN) fishery ${ }^{1}$ is one of these five federally

\begin{abstract}
${ }^{1}$ There are two other entangling net fisheries off the coast of California besides the large-mesh California drift gillnet fishery, including a set net fishery and the small-mesh drift gillnet fishery that targets white seabass, Atractoscion nobilis. Only the large-mesh fishery targets HMS sharks and swordfish.
\end{abstract}

Laura C. Urbisci (lurbisci@gmail.com) is with the Bren School of Environmental Science and Management, 2400 Bren Hall, University of California, Santa Barbara, CA 93106. Stephen M. Stohs and Kevin R. Piner are with the Southwest Fisheries Science Center, National Marine Fisheries Service, NOAA, 8901 La Jolla Shores Drive, La Jolla, CA 92037.

doi: dx.doi.org/10.7755/MFR.78.3-4.1 managed HMS fisheries, along with the albacore, Thunnus alalunga, surface-hook-and-line fishery, the tuna purse seine fishery, the deep-set longline tuna fishery, and the harpoon swordfish, Xiphias gladius, fishery.

California's HMS fisheries have generally declined from their peak in the 1960 's, when the tuna purse seine fishery targeting Pacific bluefin tuna, Thunnus orientalis, was one of the largest tuna fisheries (Calkins, 1982). However, after the closure of the Mexican Exclusive Economic Zone (EEZ) to U.S. commercial vessels in the late 1970's, the U.S. tuna purse seine fleet largely disappeared (Hanan, 1983). Although the albacore surface-hookand-line fishery (Dotson and Center ${ }^{2}$ ) appears to be operating near historical capacity, swordfish fleets have experienced a similar decline in recent years

${ }^{2}$ Dotson, R. C. 1980. Fishing methods and equipment of the U.S. west coast albacore fleet. U.S. Dep. Commer., NOAA, Natl. Mar. Fish. Serv., Southwest Fish. Sci. Cent., NOAA-TMNMFS-SWFC-8, $126 \mathrm{p}$. to that of the purse seine fleet in terms of participation, effort, catch, landings, and revenues.

The west coast swordfish fishery has primarily utilized three methods of fishing in recent decades: harpoon, shallow-set longline, and drift gillnet. A harpoon swordfish fishery has operated off the U.S. west coast since ancient times, with the modern fishery beginning around the early part of the $20^{\text {th }}$ century. While having little bycatch, the inefficiency of this gear type resulted in much of the fleet switching to the DGN fishery in the 1980's (Coan et al., 1998). The DGN fishery was state-managed before 2004, at which point existing state regulations were incorporated into the Federal HMS FMP, but the permit system continued to operate under California state law.

In the 1990's a pelagic longline swordfish fishery operated off the U.S. west coast; however, shallow-set longline gear was not authorized as a legal gear for targeting swordfish off
ABSTRACT-The California drift gillnet fleet has operated off the U.S. west coast since it developed in the late 1970's. At its full extent, fishing effort ranged from the Southern California Bight north to Oregon. The fishery initially targeted pelagic sharks (family Alopiidae), but shifted targets in the mid-1980's to swordfish, Xiphias gladius, due to the species' higher value and to the regulatory changes which created an economic advantage for targeting swordfish compared to thresher shark, Alopias vulpinas. Consequently the number of participants in the once-small fleet substantially increased. Conservation concerns over the entanglement of nontarget species, including sharks, sea turtles (family Dermochelyidae and Cheloniidae), and marine mammals, led to the enactment of a series of time and area closures over a period of 19 years to reduce the bycatch of those species. As a result, the fishery declined dramatically.

This paper analyzes catch and effort data for the fishery to determine the effects of these management measures on targeted pelagic sharks and swordfish catch per unit of effort (CPUE). Unlike traditional catch-rate analysis, which seeks to standardize fishing effort heterogeneity to produce a measure of relative stock abundance, our analysis uses a linear regression of set-level catch counts on time and area combinations where fishing occurred over the full period for which data is available to estimate the effects of time and area closures on fishery catch rates while controlling for population abundance trends. Resampling methods are used to quantify uncertainty in the estimates. The analysis documents reduced common thresher and shortfin mako shark, Isurus oxyrinchus, CPUE resulting from effort shifting out of higher to lower catch rate areas.

Before the 2001 establishment of the Pacific Leatherback Conservation Area (PLCA) closure which eliminated most effort in the fishery north of Pt. Conception, the fishery operated from the Mexican territorial water border northward to Oregon. The cumulative effect of all enacted time and area closures was to concentrate fishing effort within the Southern California Bight, likely contributing to a decline in vessel participation. The socioeconomic impacts on the operation of the fishery and on the usefulness of drift gillnet CPUE data for stock assessments are discussed. 


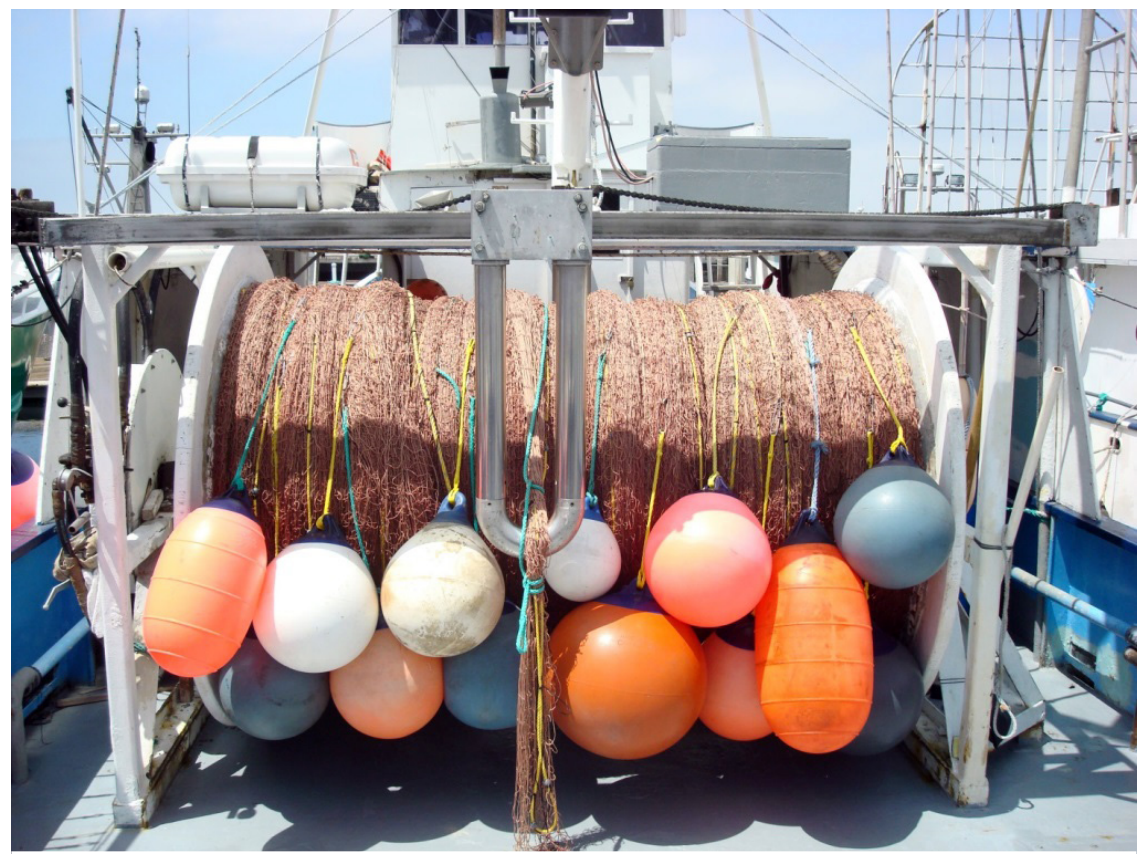

Figure 1.-Net reel and bumper-ball floats on a DGN vessel (Photo: Stephen Stohs, NOAA).

the west coast under the HMS FMP when it took effect in 2004, due to concerns over the level of endangered loggerhead sea turtle, Caretta caretta, interactions and over possible negative impacts of longline fishing on the quality of the recreational HMS fishing experience. The current range of participation within the EEZ in the west coast swordfish fishery includes groups of fishermen exclusively using either DGN or harpoon, as well as a group using both gears: DGN gear if fished overnight and harpoon used opportunistically to target swordfish individually at the surface by day.

\section{Drift Gillnet Fishery Overview}

The components and operations of DGN gear used to target HMS have remained relatively consistent from the onset of the fishery until the present, with only moderate changes in mesh size and set depths. Drift gillnet gear consists of a panel of netting that is suspended vertically in the water by floats with weights at the bottom (Fig. 1 ). One end of the net is fastened to the vessel and the other end of the net is left free to drift along the current. Fishing usually takes place in proximity to oceanic features that attract and hold fish, with the nets set perpendicular to currents, or across temperature, salinity, or turbidity fronts.

To further limit interactions with diurnally active protected species, nets are set in the evening and allowed to soak overnight. The average soak time is approximately $10 \mathrm{~h}$ with net retrieval beginning at sunrise. Large meshes ( $\geq 14$ in) are currently required in the HMS DGN fishery to reduce bycatch of smaller, unwanted species and to optimize the catch of larger more desirable fishes, such as pelagic sharks and swordfish (NMFS, 2013). The requirement for a uniform large mesh size makes HMS DGN gear highly selective for pelagic market species such as swordfish; common thresher shark, Alopias vulpinas; and shortfin mako shark, Isurus oxyrinchus, as small or undersized fish are able to swim through the mesh unharmed, whereas excessively large fish are unable to penetrate the mesh sufficiently to become trapped (Jennings et al., 2009).
The concept of targeting pelagic sharks off the coast of California was inspired by the occasional incidental catch of sharks in the nearshore small mesh gillnets that targeted California barracuda, Sphyraena argentea, and white seabass, Atractoscion nobilis (Hanan et al., 1993). When it developed in the late 1970's, the DGN fishery originally targeted pelagic sharks in the nearshore waters of the Southern California Bight (SCB), but it shifted targets in the mid-1980's to swordfish due to the species' higher value and to the regulatory changes which created an economic advantage for targeting swordfish compared to thresher shark.

The fishery initially targeted common thresher and other large pelagic sharks; however, fishermen soon realized that their nets were also efficient at catching swordfish. Swordfish had nearly four times the market value (Bedford, 1987; Holts, 1988) and were abundant, making the take of swordfish a more profitable operation.

In the earliest years of the DGN fleet, swordfish catches were constrained by regulations linking the ratio of the landings of swordfish to sharks; nevertheless, the potential value of a swordfish fishery to California resulted in the easing of those restrictions in the early 1980's.

A shark conservation closure $75 \mathrm{nmi}$ off the coast during the spring pupping season increased the economic advantage of targeting swordfish over pelagic sharks. The fleet responded to the changing incentives by subsequently shifting their primary target from pelagic sharks to swordfish and by increasing participation in the DGN fishery. The newly formed DGN fleet started with only 15 vessels but rapidly increased fleet capacity to around 230 vessels by 1985 (Hanan et al., 1993).

The burgeoning DGN swordfish fishery encountered conflicts with other fishing sectors and constituents. As the fishery expanded, the commercial harpoon fishery expressed concerns over reduced swordfish availability, and the recreational hook-and-line fishery expressed fears over bycatch of striped marlin, Kajikia audax. Inci- 
dental catch of marine mammals, particularly California sea lions, Zalophus californianus, caught near the Channel Islands, brought conflicts with marine mammal advocates.

Increasing awareness of the importance of top predators to the California Current Ecosystem renewed concerns over the population status of large pelagic sharks. In addition, the coastal California DGN effort was confounded with large-scale high-seas gillnetting, which was widely believed to be a "dirty" and destructive fishing practice (Johnson et al., 2005; Bull, 2007). Given these concerns and the fact that very little was known about the population status or biology of thresher sharks $\left(\right.$ Berkson $\left.^{3}\right)$, laws were enacted to regulate the DGN fishery.

Besides mandatory gear restrictions and bycatch reduction measures, including requirements for pingers and 6-fathom net extenders to reduce marine mammal interactions and for a minimum 14 in mesh size, the primary regulatory mechanism to reduce the take of targeted and bycatch species in the large-mesh DGN fishery has been the use of time and area closures (PFMC, 2011). In 1982, the EEZ within $200 \mathrm{nmi}$ of California was closed from 1 February to 30 April.

Then in 1985 , state regulatory measures were enacted in California to implement three major management changes: fishermen were only allowed to target thresher sharks in May, as DGN effort was not permitted within $75 \mathrm{nmi}$ of the coast from 1 June to 14 August, and the area within $25 \mathrm{nmi}$ off the California coast was off limits from 15 December to 31 January. The 75 nmi closure's timeframe was changed in 1989 from 1 May to 14 July and then was expanded in 1992 by extending the closure from 1 May to 14 August. This is sometimes referred to as the thresher shark closure, since its intent was to eliminate the direct targeting of thresher shark by DGN in time and area combinations of conservation concern (Table 1, Fig. 2).

${ }^{3}$ Berkson, J. M. 1985. A population analysis of the common thresher shark (Alopias vulpinus). Contract rep. to Calif. Dep. Fish Game, p. 16.

Table 1.-Key management changes within the DGN fishery. Data obtained from Hanan et al. (1993) and Fishery Management Plan and Environmental Impact Statement for U.S. West Coast Fisheries for Highly Migratory Species (PFMC, 2003).

\begin{tabular}{|c|c|}
\hline Year & Management changes \\
\hline 1980 & $\begin{array}{l}\text { California establishes a nontransferable limited entry program, allows fishermen to retain swordfish, creates } \\
\text { the logbook program, and establishes } 6,000 \mathrm{ft} \text { as the maximum DGN length. }\end{array}$ \\
\hline 1982 & $\begin{array}{l}\text { California issues a moratorium on the issuance of new permits and establishes a requirement that each } \\
\text { vessel can land no more swordfish than shark by weight per month from } 1 \text { May to } 15 \text { September (50-50 } \\
\text { quota). The fishery closes from } 1 \text { February to } 30 \text { April within } 200 \mathrm{nmi} \text { and around portions of the Channel } \\
\text { Islands. }\end{array}$ \\
\hline 1985 & Shark-swordfish quota is removed from California regulations. \\
\hline 1985 & $\begin{array}{l}\text { California reduces the thresher shark fishing season to } 30 \text { days in May; fishing is prohibited within } 75 \mathrm{nmi} \\
\text { off California coast from } 1 \text { June to } 14 \text { August, and from } 15 \text { December to } 31 \text { January the fishery is closed } \\
\text { within } 25 \mathrm{nmi} \text { of the California coast. }\end{array}$ \\
\hline 1989 & California modifies the $75 \mathrm{nmi}$ thresher closure to cover the period from 1 May to 14 July. \\
\hline 1990 & Federal Fisheries Observer Program is established. \\
\hline 1992 & California extends the $75 \mathrm{nmi}$ thresher closure period from 1 May to 14 August. \\
\hline 1994 & California caps new entrants to the fishery and only allows permits to be transferred. \\
\hline 1997 & $\begin{array}{l}\text { Federal MMPA requires vessels to use acoustic pingers and to place the float line at least } 36 \mathrm{ft} \text { below the } \\
\text { surface water. }\end{array}$ \\
\hline 2001 & $\begin{array}{l}\text { The DGN fishery is closed under the Federal Endangered Species Act to protect the leatherback sea turtles } \\
\text { from } 15 \text { August to } 15 \text { November, covering an area north of Pt. Sur, including the offshore waters to Pt. } \\
\text { Conception, and extending north to lat. } 45^{\circ} \mathrm{N} \text {. A second Federal ESA turtle closure is implemented in the } \\
\text { area south of Pt. Conception and is designed to protect the loggerhead sea turtles only during forecast or } \\
\text { occurring El Niño events from } 1 \text { June to } 31 \text { August. }\end{array}$ \\
\hline 2002 & $\begin{array}{l}\text { California establishes a requirement for permit holders to purchase a permit every year to remain in the } \\
\text { fishery, but permit holders are not required to land every year. }\end{array}$ \\
\hline 2004 & Establishment of Federal fishery management plan for highly migratory species. \\
\hline
\end{tabular}

The last major time and area closures were established in 2001 when DGN fishermen were subsequently prohibited from fishing within a $160,000 \mathrm{nmi}^{2}$ quadrant called the $\mathrm{Pa}$ cific Leatherback Conservation Area (PLCA) from 15 August to 15 November. Similarly, an area in the SCB was designated as a loggerhead turtle closure to protect the species during El Niño seasons when oceanic conditions increase the chances of their occurrence inside the west coast EEZ.

The DGN fleet has been monitored by observers nearly since the onset of the fishery, first by a limited California observer program (Hanan et al., 1993) and subsequently through a Federal Fisheries Observer Program established by the National Marine Fisheries Service (NMFS). Under the authority of the Marine Mammal Protection Act, federal observers were given the responsibility to record information on all species caught on observed sets of DGN fishing. In addition to collecting information on marine mammal interactions, the observers also collected high quality information on fishing behaviors and catch which is presumed to be less biased than information self-reported by fishermen on trip logs. Data from observers have been used not only to validate the selfreported logbook program (Walsh et al., 2005), but they also are often the focus of CPUE standardization for use in stock assessments (Walsh et al., 2009).

Limiting fishing effort through time and area closures to protect bycatch of nontargeted species can have unintended consequences on the catch rates of both the target and nontarget species. In this paper we document the effects of time and area closures on DGN fishery. We use a simple statistical approach to account for changes in population abundance to estimate the effects of time-area closures on catch rates. We examined the catch rates of four species that composed the majority of the DGN catch: swordfish; common thresher shark; shortfin mako; 


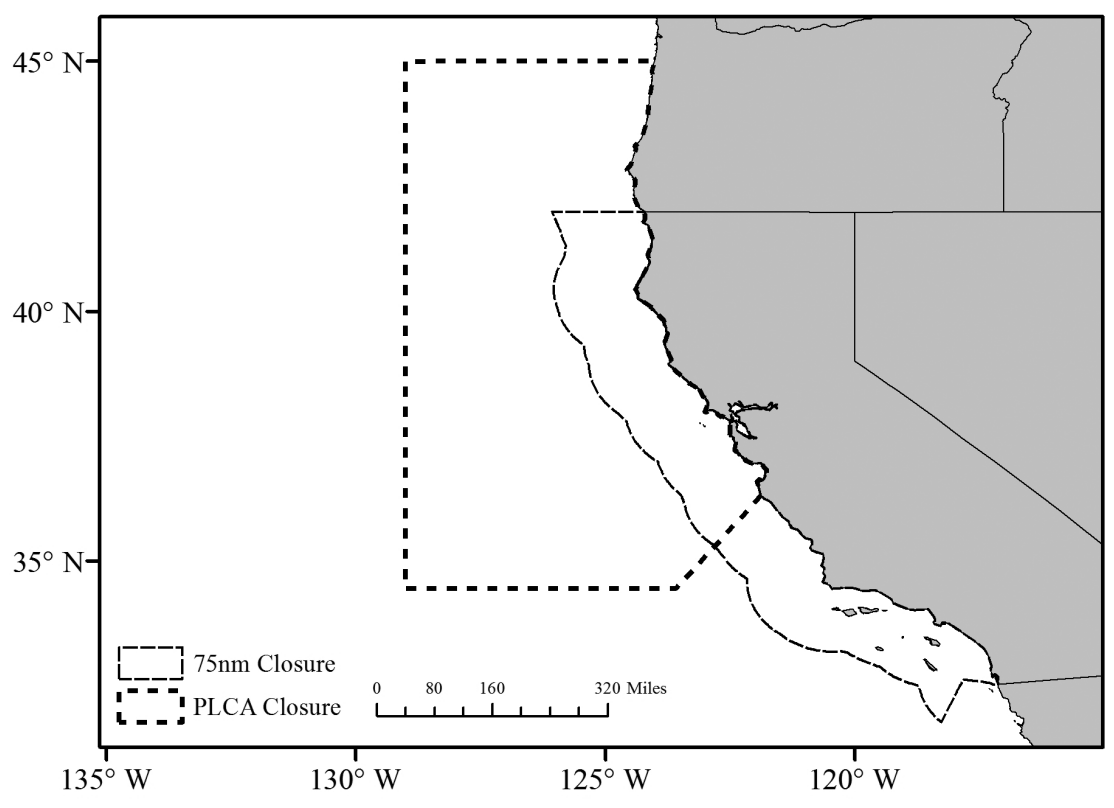

Figure 2.-The two main DGN fishery closures.

and blue shark, Prionace glauca. The discussion focuses on how regulations intended to protect sharks, marine mammals, and endangered seas turtles can have both intended and unintended consequences on commercial fisheries. We also address how management related shifts in fishing effort can result in misleading estimates of CPUE when they are used as measures of relative abundance without standardizing in the assessment to reflect the exogenous changes in the spatial-temporal distribution of effort.

\section{Data}

\section{Methods}

Data for this study include California Department of Fish and Wildlife (CDFW) issued DGN trip logbooks from 1981 to 2012 and data collected by the NMFS West Coast Region observer program from 1990 to 2013. Logbooks are self-reported data from captains; while compliance is high among fishermen who submit logbooks, not all fishermen return them. Observers provide records of fishery operations from a sample of slightly less than $20 \%$ of all trips, with fishery independent information provided by biologists who are trained to collect the data while onboard DGN trips.

Both datasets include information on the trip number, set number, date, effort, and catch counts for all thresher, shortfin mako, and blue sharks, as well as swordfish. The observer dataset contains latitude and longitude coordinates, while the logbooks provide the California Department of Fish and Wildlife block locations; hence the observer data are more fully representative of the exact locations of fishing effort and the spatial extent of the fishery, but they are limited to the less than $20 \%$ of effort with observer coverage since the program took effect in 1990. Both of the data sets had a small number of observations missing latitude-longitude coordinates. We did not believe these values would significantly impact our results, and hence we ignored the potential effect of missing observations on our results.

We conducted our analyses of thresher and shortfin mako sharks as well as swordfish using the logbook data, as catch counts for these commercially valuable species are presumed to be accurately recorded by captains. We used the observer data for blue shark, a less commercially valuable species with a lower retained catch rate, on the presumption that catch of species with limited commercial value and few landings may be underreported on trip logs.

Records from the logbook and observer data included for the study are for trips which used drift gillnet to target swordfish and HMS sharks. Although observer data represents only a fraction of the effort recorded in logbooks, observer records of undesirable catch are presumed to represent a more accurate measure of catch rates due to systematic inclusion of discards in observed catch counts.

Fishing effort (in sets) was categorized into areas and seasons corresponding to the time-area closures examined by our analysis. Observations were first filtered for missing latitude and longitude data needed for area determination. ${ }^{4}$ For the remaining observations, the Haversine great circle distance measure was used to approximate the set location's distance from shore taking into account the curvature of the earth. We classified each observation as to whether it occurred within the area and during the time of either the thresher shark or PLCA closure based on location and date (Fig. 2).

\section{Analysis}

To estimate the effects of establishing the thresher shark closure and subsequent PLCA closure on the DGN fleet CPUE, we used linear regression analysis to estimate the set level catch rates corresponding to allowable effort that was either eliminated or continued under the time and area closures. Potential changes in species' abundance and nonclosure management measures implemented through time (Table 1) were accounted for by producing estimates using data over the full period

${ }^{4} 16,131$ out of 122,880 logbook records $(13.1 \%)$ were missing latitude-longitude or other key information, leaving 106,749 $\log$ s for swordfish, common thresher shark, and shortfin mako shark analysis; 202 out of 8,491 observer data records $(2.4 \%)$ lacked latitude-longitude coordinates or other information, so 8,289 observations were available for blue shark analysis. 
for which it is available. A resampling procedure was used to quantify uncertainty in the estimates.

$$
\begin{aligned}
& y_{i}^{k}=\beta_{s(i) a(i)}^{k}+\eta_{t(i)}^{k}+\varepsilon_{i}^{k} \\
& \text { Where, } \\
& y_{i}^{k}=\text { the number of fish of spe- }
\end{aligned}
$$

We resampled sets without replacement from all years, areas, and times that were open for fishing (19812010). On each simulation pass, a linear regression of catch rates on indicator variables for time and area of fishing and a fixed season effect was used to estimate time-area specific CPUE while controlling for time trends in CPUE.

Efron and Tibshirani (1994) discuss resampling methods for regression models, identifying two different ways of bootstrapping a regression model. Bootstrapping can resample the data set or the residuals of the linear model. The question of which method is better for a given situation depends on whether the linear regression model specification can be trusted. Our data may potentially depart from standard linear model assumptions about the independence of the error term if, for instance, different time and area combinations included in our model structure result in different error term distributions, violating the independence assumption of ordinary least squares regression. Hence we followed the suggestion by Efron and Tibshirani to bootstrap the original observations rather than the fitted residuals, thereby avoiding sensitivity of our results to linear regression model assumptions about the error terms which may not hold for our data.

To estimate the effect of each closure, we computed the mean of predicted CPUE for the portion of the resampled data representative of timearea combinations which remained open under the given closure policy. Mean catch rates for each species were computed for four scenarios: 1) no closure (corresponding to the pre1985 period), 2) thresher shark closure in isolation (approximating the period from 1985 to 1999), 3) PLCA closure in isolation (hypothetical scenario not corresponding to any period that actually occurred), and 4) both closures in effect (corresponding to the post 2000 period). Because of some overlap in the areas of the thresher shark and PLCA closures, scenario 4 is not the sum of scenarios 2 and 3 .

\section{Results}

The total DGN swordfish and HMS shark catches have declined almost linearly since the mid-1980's (Fig. 3), in close proportion to the decline in the total number of participating DGN vessels (Fig. 4). Shark catch rates outside of the time and areas closures are lower (Fig. 5). The thresher shark closure appeared to have the largest effect on thresher and shortfin mako shark catch rates, with both declining significantly (blue shark is not included in this discussion as observer coverage was not implemented until 1991).

Thresher and blue shark catch rates also declined with establishment of the PLCA closure in 2001, although the decrease for threshers is not as large as that which occurred with the thresher shark closure. In contrast, the swordfish catch rates increased with both the thresher shark and PLCA closures, but the magnitude of the effect of the PLCA closure was substantially less (Fig. 5).

The change in catch rates due to area closures may be explained by shifts in the location of effort (Fig. 6) relative to the location of high catch rates (Fig. 7). The thresher shark closure pushed effort farther offshore and also resulted in a northward shift of effort (above lat. $40^{\circ} \mathrm{N}$ ). However the implementation of the PLCA closure severely shifted effort southward, largely confining effort to the SCB (below lat. $35^{\circ} \mathrm{N}$ ). The shift of effort away from nearshore areas and to a lesser extent into the SCB moved fishing away from areas that had higher catch rates of large pelagic sharks. Thus the change in total catch of all species (Fig. 3) is a combination of decreasing effort

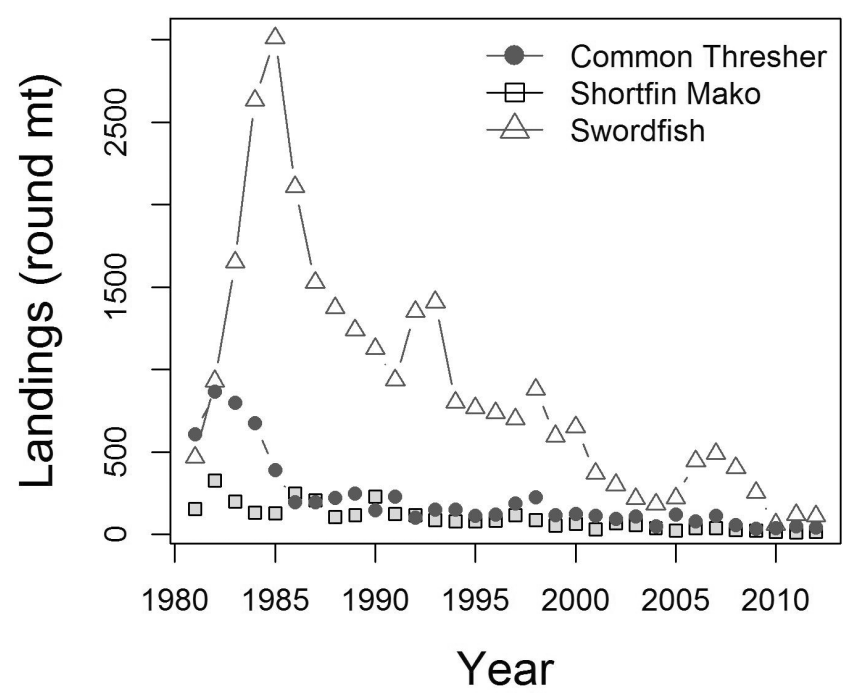

Figure 3.-Landings by species (round $\mathrm{mt}$ ) from DGN vessels 1981-2012 (PacFIN). Blue shark landings are not included as they are often discarded. 


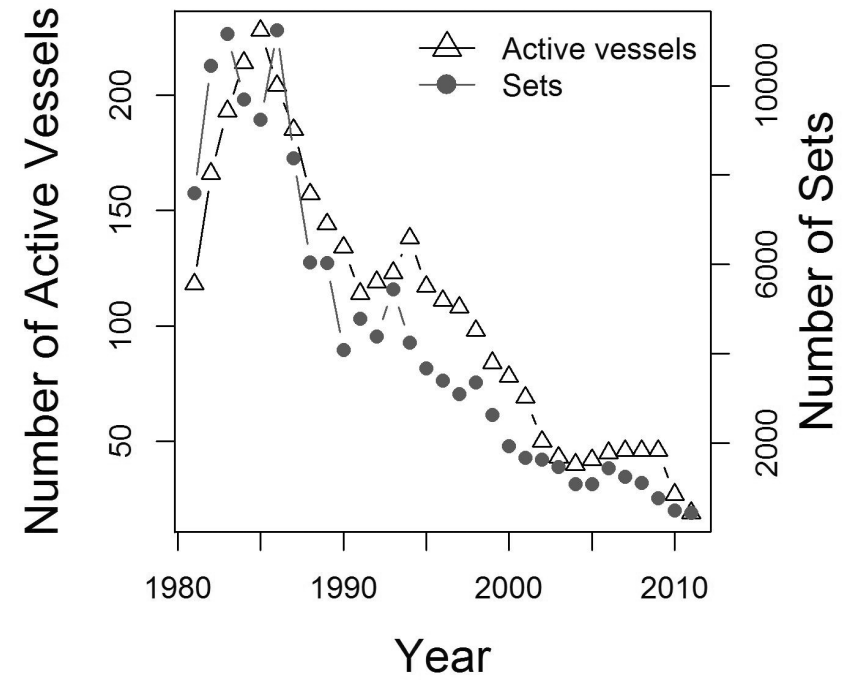

Figure 4.-The number of DGN vessels operating by year (left scale) and total number of sets fished per year (right scale) (Data from NMFS (2013) for set information from 1990-2011; data from Holts et al. (1998) for set information from 1981-89).

(Fig. 4) due to reduced areas open to fishing (Fig. 6) and, for some species, a reduced catch rate in the open areas (Fig. 5, 7).

\section{Discussion}

The reduction in times and areas open to fishing appears to have significantly impacted the structure and economic performance of the DGN fishery. Although DGN remains the sole U.S. west coast fleet with substantial levels of both HMS shark and swordfish catch, the levels of catch, effort, and revenues have declined in recent years.

Our analysis showed that shifting fishing effort to areas outside of the $75 \mathrm{nmi}$ closure during the period from 1 June through 14 August (seasonal thresher shark closure) had the desired effect of significantly reducing the catch rate of large pelagic sharks, without reducing the catch rate of swordfish (Fig. 5). In contrast, restricting effort to the SCB during the 15 August through 15 November period due to the seasonal PLCA closure led to a smaller, though still significant, reduction in the thresher shark catch rate and an insignificant impact on the mako shark catch rate; however, there was an apparent reduction in the amount of effort inside the PLCA during the summer-fall portion of the season (Fig. 6).

Given a limited reduction in catch rates of the primary target species, swordfish, due to the closure measures and the precipitous decline in effort, landings, and participation from over 200 vessels in the mid-1980's to recent numbers below 20, it raises the question of what factors explain the decline in participation and production. We believe the decline is most likely due to a combination of many factors rather than a single explanation.

One change in the fishery since its inception is an increasing cost of regulatory compliance, such as the mandatory requirements to use pingers and 36' net extenders due to the 1997 Pacific Offshore Cetacean Take Reduction Team regulations under the Marine Mammal Protection Act. Since fishermen are required to bear the costs of such bycatch reduction technology, the profitability of DGN fishing is reduced, likely explaining some of the reduction in participation.

Spatial management effects on fish- ing operations have also likely contributed to the reduction in DGN fishing effort. Establishment of the PLCA not only reduced allowable fishing effort for a time and area combination where most of the historical leatherback sea turtle interactions occurred, but it also eliminated allowable effort in profitable time-area combinations with a favorable combination of high swordfish catch rates with lower transit costs, particularly for vessels ported to the north end of the fishery.

Increased fuel costs subsequent to establishment of the PLCA further squeezed the margin of profitability, particularly in light of the need for some fleet members to travel greater distances to access the swordfish stock. The availability of foreign imports as a cheap substitute for domestic production limited the fleet's potential to raise prices to cover higher transit costs. The differential effect of the PLCA closure on DGN vessels ported north, along the closed area, compared to those ported south of the closed area, suggests a hypothesis that DGN fishermen ported in areas with close proximity to closure areas saw larger drops in effort and participation than fishermen farther away. A disproportionally high impact of the regulatory cost of closures likely was borne by vessels with high shares of historic effort in time-area combinations which were disallowed by closures, as their remaining opportunities to successfully fish during closed seasons are either located in more distant waters, implying higher transit costs, or in less productive time-area combinations than those chosen before regulation. By contrast, fishermen ported farther away from closures, whose traditional fishing effort with respect to time and location remained open after time-area regulations, would be expected to bear less regulatory costs of lost opportunity to fish profitably; hence this group would be more likely to remain in the fishery.

The stable swordfish CPUE trend may reflect countervailing effects of declining vessel participation, due to reduced fishing opportunity, and sur- 


\section{Estimates of Mean Closure Effects on Swordfish CPUE}

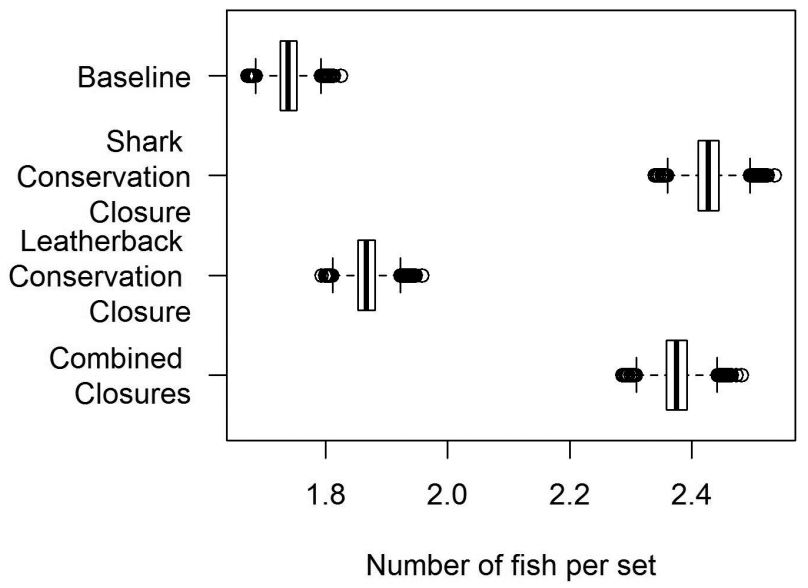

Estimates of Mean Closure Effects
on Blue Shark CPUE

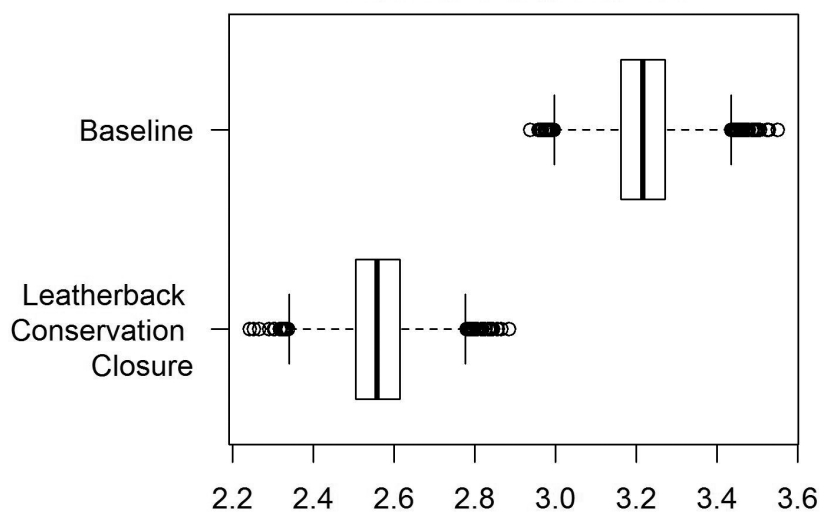

Number of fish per set

\section{Estimates of Mean Closure Effects} on Thresher Shark CPUE

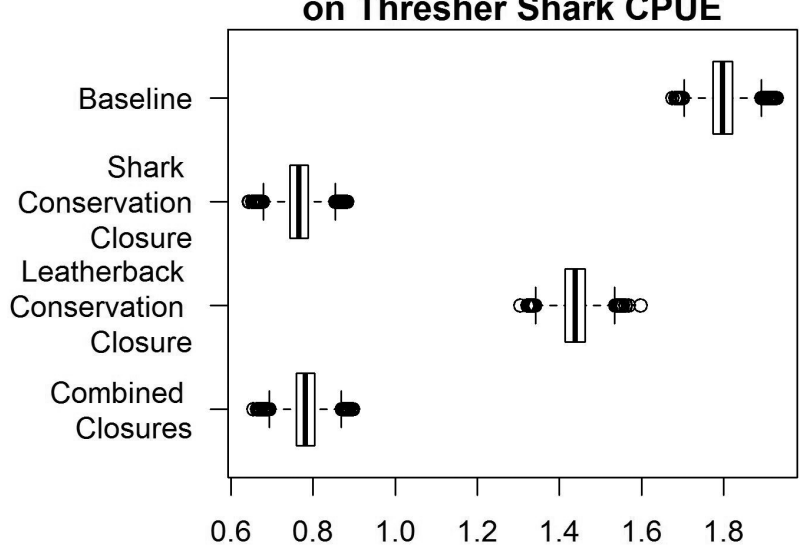

Number of fish per set

\section{Estimates of Mean Closure Effects on Shortfin Mako Shark CPUE}

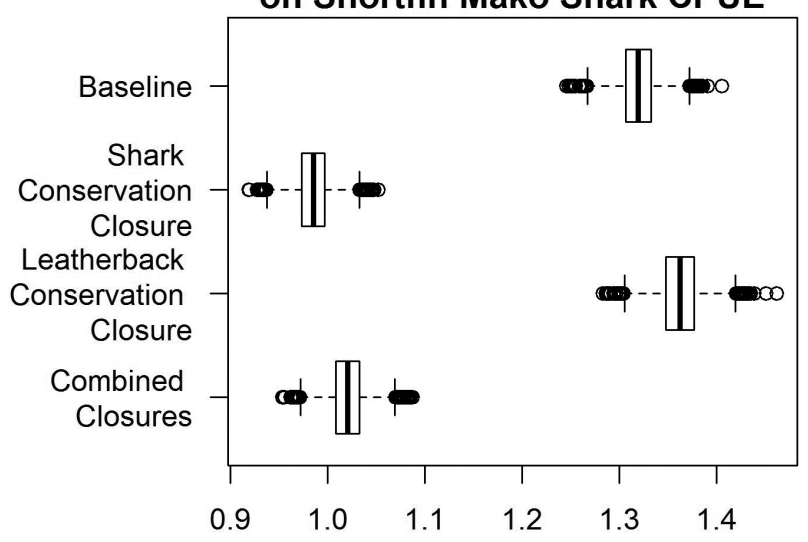

Number of fish per set

Figure 5.-Bootstrapped estimates of shortfin mako, thresher, blue shark, and swordfish CPUE under the shark area and PLCA closures, the combination of both closures, and no closure (baseline). Box-and-whiskers plots show the first, second (median), and third quartiles of bootstrap simulation estimates (hinges on box) with notches at $+/-1.58 \mathrm{IQR} / \mathrm{sqrt}(\mathrm{n})$; outliers are displayed outside the notches. Individual panels have their own unique axes to maximize the interpretation of the boxes.

vival of the most efficient producers. Swordfish CPUE experience reflects selectivity bias, as the fishermen whose costs would have increased or CPUE would have decreased due to regulation dropped out while those who were able to maintain a favorable balance of CPUE and sales revenues against the costs of accessing the resource stock continued their participation.

While the limited entry permit system served to limit competition in the fishery and effectively established an effort control on finfish and bycatch impacts of DGN fishing, the requirement to renew DGN permits in each year or else lose them naturally leads to diminished fleet size over time. However, a large gap between the numbers of active permits and the total number of permits which could be fished indicates that a group of fishermen maintain hope that changes in regulations or other factors influenc- ing economic viability could result in a restoration of profitable DGN fishing opportunity at some future point.

Although the effects of closures on all species' catch rates was mixed, the net effect of limiting seasonal availability of traditional fishing areas has been to dramatically reduce total fishing effort and catch from this fleet. These spatial fleet effects combined with California State measures capping the number of DGN vessels 

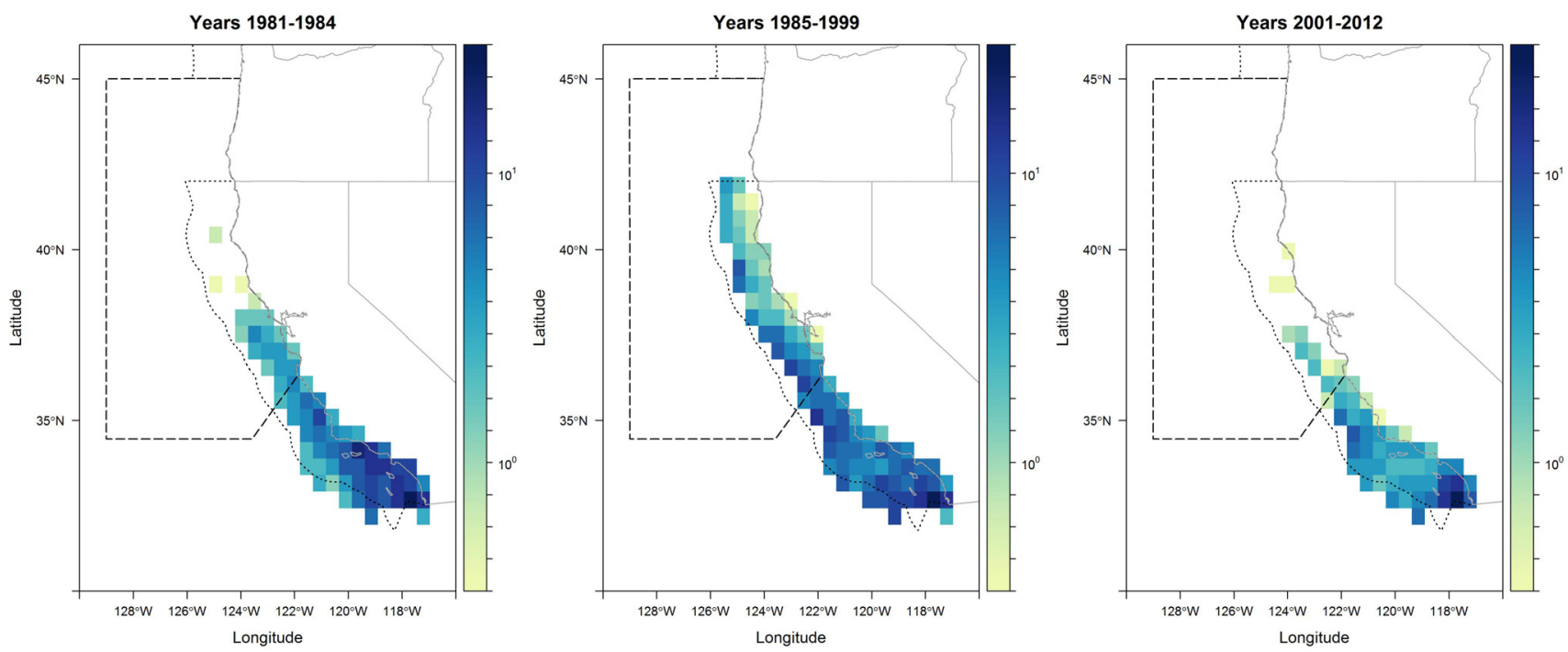

Figure 6.-Distribution of DGN effort in the period representing preclosure (1981-84), post-shark seasonal area closure (198599), and post PLCA closure (2001-10). Effort is given in 1x1 degree block. Effort is limited to extent of CDFW block coding system, so effort further offshore is excluded.

(1980) and capping new entrants to the fishery (1994) has ensured that the fishery participation could only decline.

The current limitations on DGN fishing opportunities is especially difficult on fishermen because the stock of swordfish off California appears to have been quite stable and above the levels associated with maximum sustainable yield (ISC, 2014). U.S. and worldwide swordfish consumption demand is strong as fears of mercury contamination have subsided (Lipton, 1986). However, this demand for swordfish has not been met by other west coast fisheries, given the lost production from the decline in the
DGN fishery. The harpoon fishery has showed no increase in swordfish landings or revenues in recent years (PFMC, 2015).

A Hawaii-based shallow-set longline fleet that uses circle hooks and mackerel-type bait (Walsh et al., 2009) began landing swordfish on the U.S. west coast after reopening in 2004.
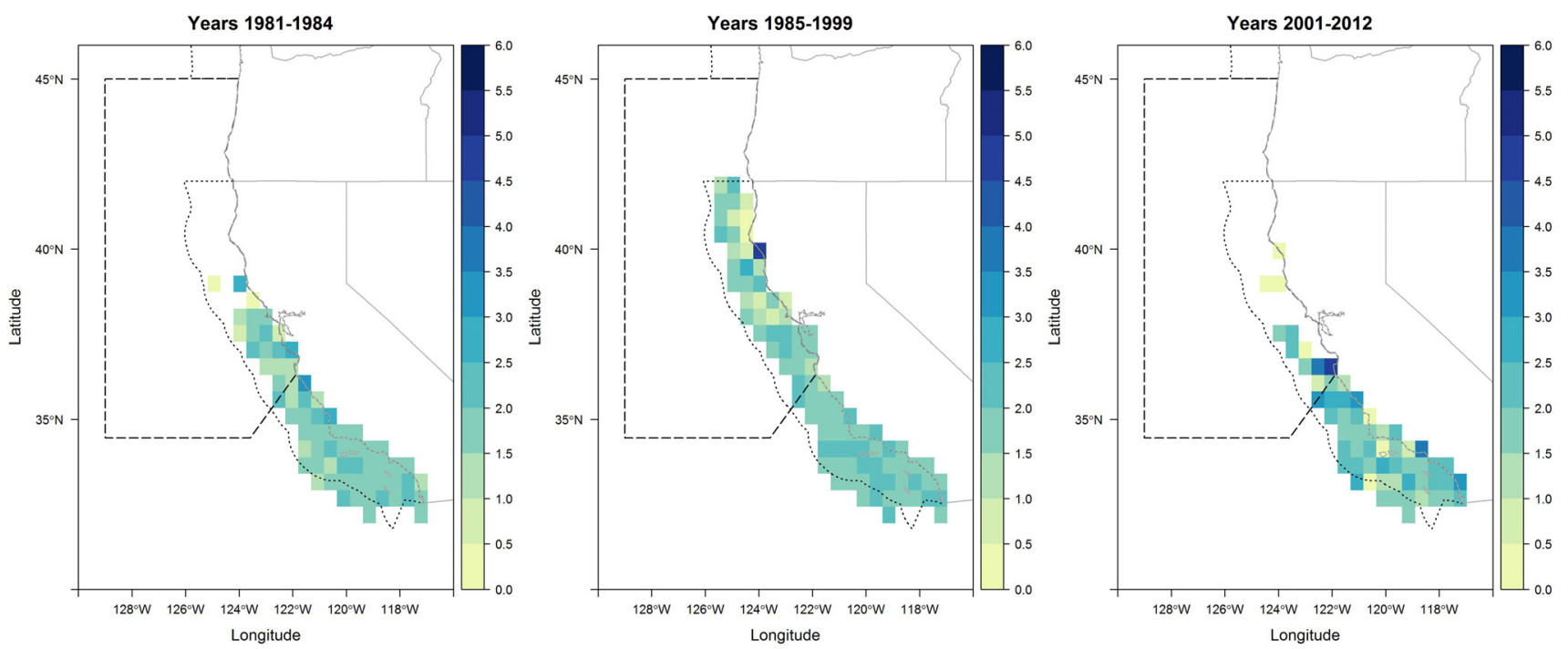

\section{Swordfish CPUE}

Figure 7.-Distribution of CPUE in the period representing preclosure (1981-84), post-shark seasonal area closure (1985-99), and post PLCA closure (2001-10). CPUE is given in 1x1 degree block for thresher, shortfin mako, and blue sharks as well as swordfish. Figure continued on next two pages. 


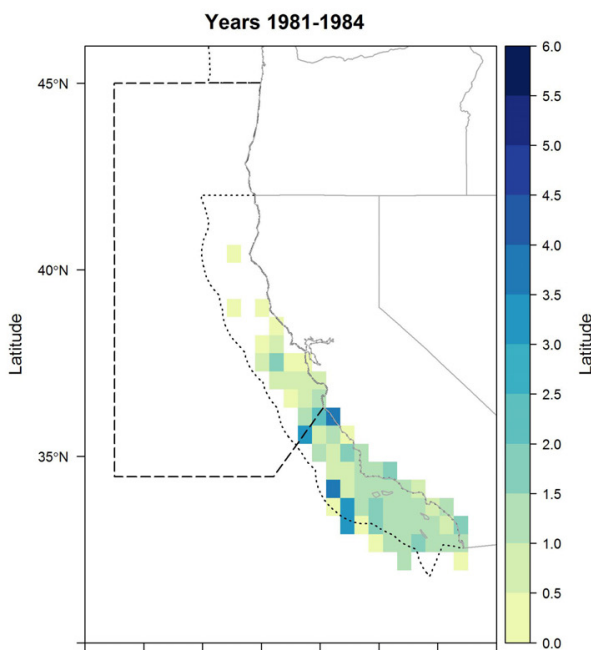

$128^{\circ} \mathrm{W} \quad 126^{\circ} \mathrm{W} \quad 124^{\circ} \mathrm{W} \quad 122^{\circ} \mathrm{W} \quad 120^{\circ} \mathrm{W} \quad 118^{\circ} \mathrm{W}$ Lonaitude

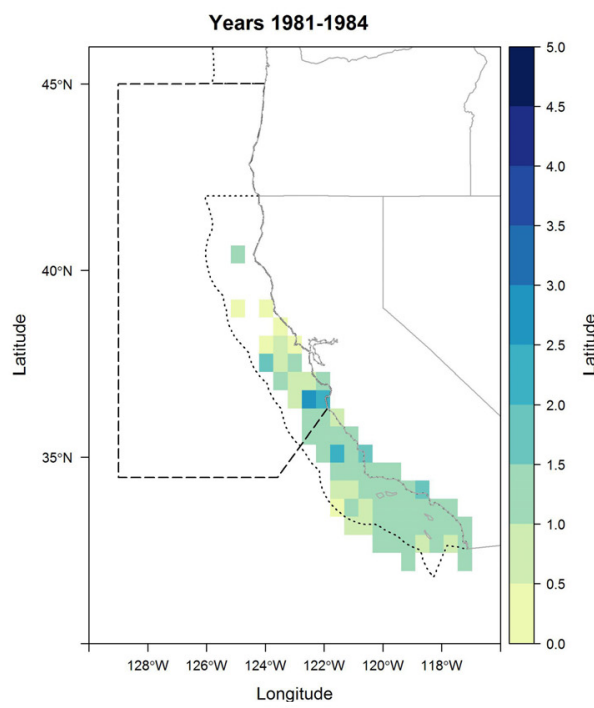

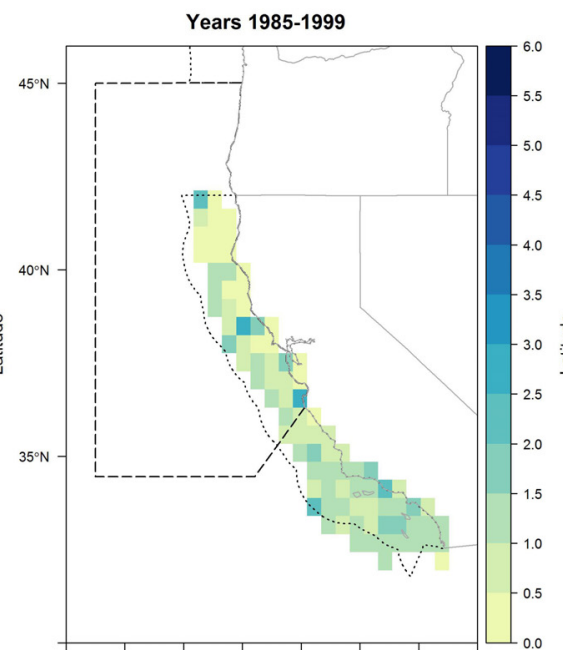

$128^{\circ} \mathrm{W} \quad 126^{\circ} \mathrm{W} \quad 124^{\circ} \mathrm{W} \quad 122^{\circ} \mathrm{W} \quad 120^{\circ} \mathrm{W} \quad 118^{\circ} \mathrm{W}$ Lonaitude

Thresher CPUE

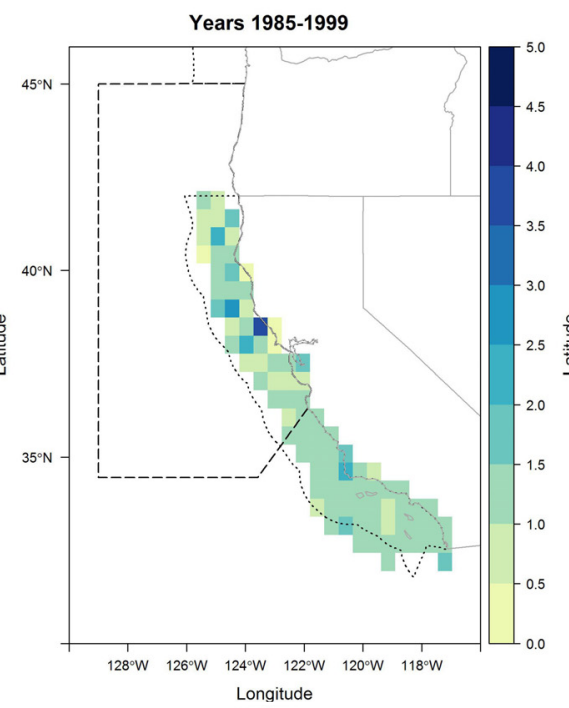

Shortfin Mako CPUE

Figure 7.-Continued.
This gear combination has been shown to reduce the rate of endangered sea turtle interactions by nearly $90 \%$ from pre-2001 rates, but such gear was never approved for use in the West Coast HMS FMP (PFMC, 2015). Therefore any supply increase to satisfy unmet swordfish demand must have been due to imports.

The United States imports swordfish from a wide range of countries with potentially different attitudes toward conservation, including Canada, Panama, and Singapore. It is possible that restricting effort in the U.S. fishery may result in increased effort in foreign fisheries that may impose an even larger risk to the target stock and all bycatch species (Rausser et al., 2009).

In traditional stock assessments, catch rate data is typically used as a proxy for relative changes in stock
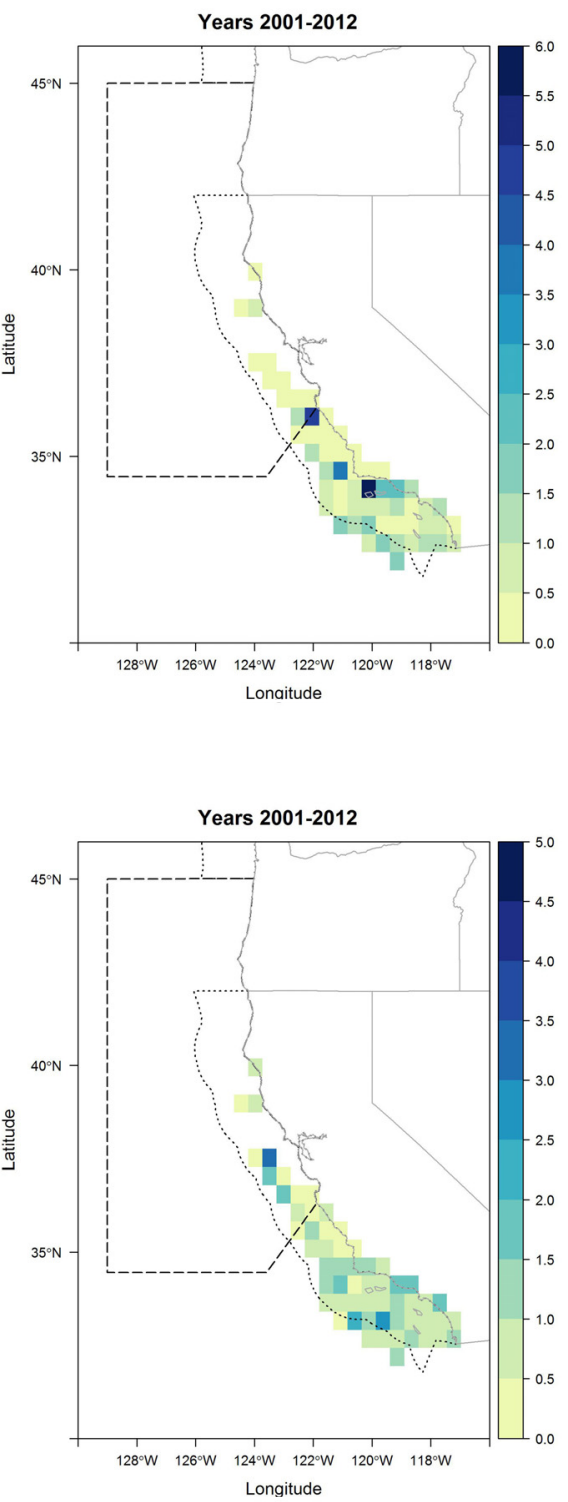

abundance after appropriate standardization of changes in fishery practices (Maunder and Punt, 2004). In contrast, this work used a bootstrapping procedure to account for changing abundance to isolate the impacts of management measures on fishery catch rates. We included a fixed-year effect in our model to account for the influence of annual-level factors such as changing stock abundance and 

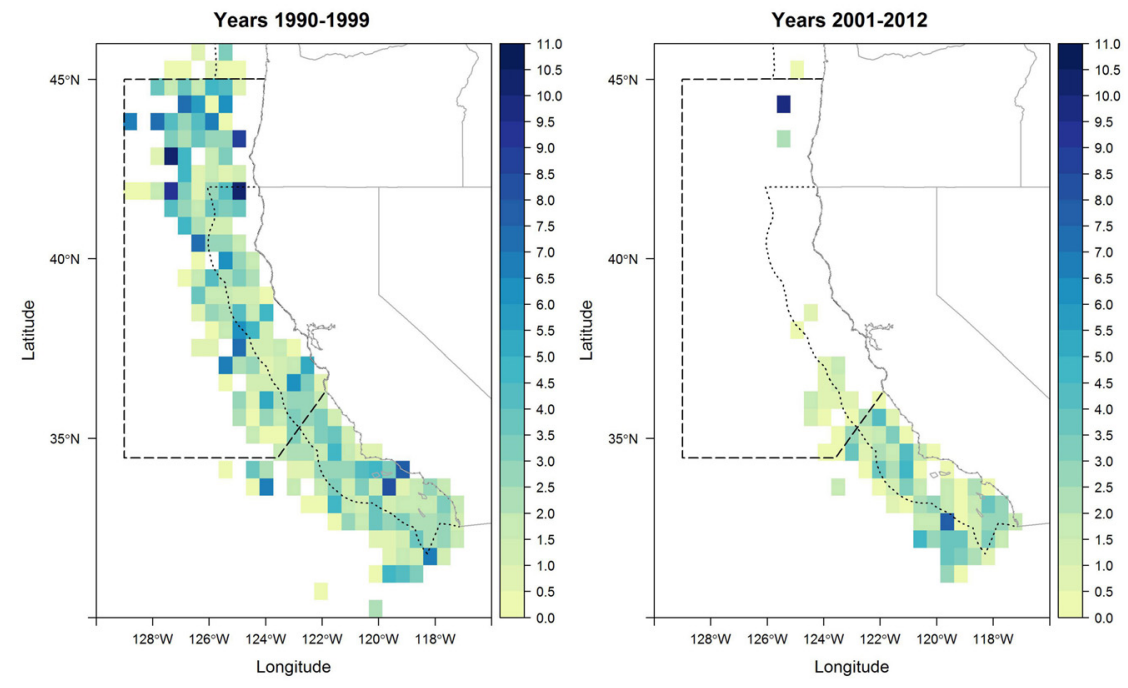

Blue CPUE

Figure 7.-Continued.

management measures not analyzed in this paper; however, we cannot be certain these were completely accounted for by the resampling methods.

Since each observation in our data represents a set-level catch count conditional on a single unit of closely-similar fishing effort, intrinsically limiting potential heteroscedasticity in the observation-level residual variance, we assume that heteroscedasticity is not a concern to our analysis. We also expect the potential efficiency gains due to modeling and estimating heteroscedasticity to be limited, given the weak correlation across time or space and the absence of any explanatory variable in our model which could potentially explain variation in residual variance. We further note that ordinary least squares is asymptotically efficient, and our sample size is very large.

A measurement problem of potential concern regards the confounding influence of removing the regulation requiring a fixed ratio of landed shark to swordfish on the effect of the thresher shark closure. Swordfish had, and continue to have, higher ex-vessel prices than the pelagic sharks, making them a more economically desirable species. Thus, the removal of shark to swordfish landing ratios likely also led to the reduced catch rates of threshers and increased catch rates of swordfish through the increased targeting of swordfish.

Beyond the impact of the regulations on the fishery, our analysis demonstrates the need to understand regulatory effects on a fishery when using CPUE as a proxy for relative abundance for stock assessment. This result applies to both targeted and nontargeted species. In the case of the DGN fleet, the primary influence of management regulations was a shifting of fishing effort into different areas as well changing the target of the fleet.

Some changes in spatial patterns appeared to influence catch rates while other shifts were not as influential. The spatial effects varied by species, making generalization of the effects of management difficult. It may be possible to standardize these spatial effects (Maunder and Punt, 2004), but the targeting effects might be more difficult to remove because they likely occur at a finer spatial scale. Of equal concern is the representativeness of the small number of participants left in the fishery and the reduced spatial areas fished of the entire target stock popu- lation range. The potential usefulness of the DGN fleet for providing population trend signals on pelagic stocks has likely dwindled with overall fleet capacity. Given public perceptions that drift gillnet is a high bycatch gear, the sun may finally be setting on the DGN fleet.

\section{Acknowledgments}

The authors thank California Department of Fish and Wildlife (CDFW) for developing the logbook program and the staff at the NMFS West Coast Region responsible for running the observer program that provided the data for this study. We also thank several scientists with both CDFW and the NMFS SWFSC for help in understanding and compiling the data. In addition, the authors thank several reviewers, both known and anonymous.

\section{Literature Cited}

Bedford, D. 1987. Shark management: a case history - the California pelagic shark and swordfish fishery. In Sid Cook (Editor), Sharks: an inquiry into biology, behavior, fisheries, and use, p. 161-171. Oreg. State Univ. Ext. Serv., Corvallis.

Bull, L. S. 2007. Reducing seabird bycatch in longline, trawl and gillnet fisheries. Fish Fish. 8(1):31-56. (doi: https://doi. org/10.1111/j.1467-2979.2007.00234.x).

Calkins, T. P. 1982. Observations on the purseseine fishery for northern bluefin tuna (Thunnus thynnus) in the eastern Pacific 
Ocean. Inter-Am. Trop. Tuna Comm. Bull. 18(2):121-225.

Coan, A. L. Jr., M. Vojkovich, and D. Prescott. 1998. The California harpoon fishery for swordfish (Xiphias gladius). In I. Barrett, O. Sosa-Nishizaki, and N. Bartoo (Editors), Biology and fisheries of swordfish, Xiphias gladius. Pap. from the Int. Symp. on Pac. Swordfish, Ensenada, Mex., 11-14 Dec. 1994, p. 37-48. U.S. Dep. Commer., NOAA Tech. Rep. NMFS 142.

Efron, B., and R. J. Tibshirani. 1994. An introduction to the bootstrap. CRC Press, Baton Rouge, La., 436 p.

Hanan, D. A. 1983. Review and analysis of the bluefin tuna, Thunnus thynnus, fishery in the Eastern North Pacific Ocean [USA]. Fish. Bull. 81:107-119.

D. B. Holts, and A. L. Coan, Jr. 1993. The California drift gill net fishery for sharks and swordfish, 1981-82 through 1990-91. Calif. Dep. Fish Game, Fish Bull. $175,95 \mathrm{p}$.

Holts, D. B. 1988. Review of U.S. west coast commercial shark fisheries. Mar. Fish. Rev. 50(1):1-8.

A. Julian, O. Sosa-Nishizaki, and

N.W. Bartoo. 1998. Pelagic shark fisheries along the west coast of the United States and Baja California, Mexico. Fish. Res. 39(2):115-125. (doi: https://doi.org/10.1016/ S0165-7836(98)00178-7).

ISC. 2014. North Pacific swordfish (Xiphias gladius) stock assessment in 2014. In Report of the billfish working group, p. 85. Int. Sci. Committ. Tuna Tuna-like Species in the N.
Pac. Ocean. Int. Sci. Committ. (ISC). Taipei, Taiwan.

Jennings, S., M. Kaiser, and J. D. Reynolds. 2009. Marine fisheries ecology. John Wiley \& Sons, Oxford, $432 \mathrm{p}$.

Johnson, A., G. Salvador, J. Kenney, J. Robbins, S. Kraus, S. Landry, and P. Clapham. 2005. Fishing gear involved in entanglements of right whales and humpback whales. Mar. Mammal Sci. 21(4):635-645. (doi: https://doi.org/10.1111/j.1748-7692.2005. tb01256.x).

Lipton, D. W. 1986. The resurgence of the U.S. swordfish market. Mar. Fish. Rev. 48(3):24-27.

Maunder, M. N., and A. E. Punt. 2004. Standardizing catch and effort data: a review of recent approaches. Fish. Res. 70(2):141-159. (doi: https://doi.org/10.1016/j.fishres.2004.08.002).

NMFS, 2007. Fishery Management Plan for U.S. West Coast Fisheries for Highly Migratory Species. As Amended by Amendment 1 . 2007, p. 110

2013. Biological Opinion on the continued management of the drift gillnet fishery under the Fishery Management Plan for U.S. West Coast Fisheries for Highly Migratory Species. U.S. Dep. Commer., NOAA, NMFS, SW Reg., Sustain. Fish. Div., 2 May 2013. (Online at http://www. westcoast.fisheries.noaa.gov/publications/ protected_species/marine_mammals/memo_ signed_dgn_biop_050213.pdf).

PFMC. 2003. Fishery Management Plan and Environmental Impact Statement for U.S. West Coast Fisheries for Highly Migratory
Species. Pac. Fish. Manage. Counc., Portland, Oreg., 524 p.

2011. Status of the U.S. west coas fisheries for the Highly Migratory Species through 2010, Stock Assessment and Fishery Evaluation. Pac. Fish. Manage. Counc., Portland, Oreg., 164 p. 2015. Current HMS SAFE Re-

port: Commercial Fisheries Descriptions, High Seas Longline Fishery for Swordfish and Tuna. World Wide Web. Pacific Fisheries Management Council. Accessed [6/21/2015] at http://www.pcouncil.org/ highly-migratory-species/stock-assessmentand-fishery-evaluation-safe-documents current-hms-safe-document/commercial-fisheries-descriptions/\#longline. Portland, Oreg. January 2015.

Rausser, G., S. Hamilton, M. Kovach, and R Stifter. 2009. Unintended consequences: the spillover effects of common property regulations. Mar. Policy 33(1):24-39. (doi: https:// doi.org/10.1016/j.marpol.2008.03.020).

Walsh, W. A., K. A. Bigelow, and K. L. Sender. 2009. Decreases in shark catches and mortality in the Hawaii-based longline fishery as documented by fishery observers. Mar Coast. Fish. 1(1):270-282. (doi: https://doi. org/10.1577/C09-003.1). R. Y. Ito, K.E. Kawamoto, and M McCracken. 2005. Analysis of logbook accuracy for blue marlin (Makaira nigricans) in the Hawaii-based longline fishery with a generalized additive model and commercial sales data. Fish. Res. 75(1):175-192. (doi: https:// doi.org/10.1016/j.fishres.2004.11.007). 